\title{
Adipose-derived Mesenchymal Stem Cell Therapy for Reverse Bleomycin-induced Experimental Pulmonary Fibrosis
}

\section{Xiansheng Zhao}

Fudan University

Jinyan Wu

Fudan University

Ruoyue Yuan

Fudan University

Yue Li

Fudan University

Quyang Yang

Fudan University

\section{Baojin Wu}

Fudan University

Xiaowen Zhai

Children's Hospital of Fudan University

Jiucun Wang

Fudan University

Jérémy Magalon

Aix-Marseille Universite de Provence: Aix-Marseille Universite

Winston M Zhu

Oxford School

NingWen Zhu ( $\square$ Zhuningwen@fudan.edu.cn )

Fudan University https://orcid.org/0000-0003-4224-4188

\section{Research Article}

Keywords: Mesenchymal stem cells (MSC), stem cells therapy, idiopathic pulmonary fibrosis (IPF), bleomycin

Posted Date: October 21st, 2021

DOI: https://doi.org/10.21203/rs.3.rs-977764/v1 
License: (c) (i) This work is licensed under a Creative Commons Attribution 4.0 International License. Read Full License 


\section{Abstract}

Background: Idiopathic pulmonary fibrosis (IPF) is a chronic progressive respiratory disease. Arguably, the complex interplay between immune cell subsets, coupled with an incomplete understanding in disease pathophysiology, have contributed to the paucity of successful therapies. In turn, IPF remains a fatal disease at present. Thus, with no effective therapy for either the prevention or treatment of IPF, the need for new therapies is paramount. Mesenchymal stromal/stem cell (MSC) therapy has shown promise in experimental models of IPF.

\section{Methods:}

The aim of this study was to test the therapeutic effect of adipose-derived mesenchymal stem cells in a bleomycin-induced pulmonary fibrosis model. First, MSC cells were obtained from mice, and then flow cytometry and cell differentiation culture methods were uesd to identify them. Then adult C57BL/6 mice were challenged with endotracheal instillation of bleomycin and treated with MSC concurrently for reversal models at day 14 . Experimental groups were assessed at day 14,21 , or 28 . Finally, lung fibroblasts were challenged with TGF- $\beta 1$ and treated with MSC supernatant or MSCs to explore the relevant mechanisms of pulmonary fibrosis reversal.

\section{Results:}

We successfully obtained mesenchymal stem cells from mouse adipose tissue and identified their differentiation ability and cell phenotype.We found that the presence of MSC or its supernatant could promote the proliferation and migration of lung fibrotic cells. Meanwhile, MSC supernatant could reduce lung collagen deposition, improve Ashcroft score, and reduce the gene and protein content of lung fibrosis-related substances. Bleomycin-challenged mice presented with severe septal thickening and prominent fibrosis, and this was effectively reversed by MSC treatment.

\section{Conclusions:}

In summary, this study found that MSC therapy can prevent and revert the core features of bleomycininduced pulmonary fibrosis, and the beneficial effects of MSC may be mediated via its paracrine-related cytokines. It provides further evidence for the importance of the MSC in cell therapy medicine applications.

\section{Introduction}

COVID-19 continues to spread rapidly around the world, causing in some cases severe respiratory disease and eventually death ${ }^{[1]}$. One study found that $14 \%$ of cases suffer from severe pneumonia and acute respiratory distress syndrome (ARDS), with an overall mortality rate is about $2 \%^{[2]}$. This idiopathic pulmonary fibrosis (IPF) is a chronic progressive respiratory disease characterized by clinical features such as shortness of breath, hypoxemia, and obvious lung infiltrates on imaging ${ }^{[3]}$. 
The latest mechanism studies have shown that the occurrence of IPF is closely related to the abnormal repair of alveolar epithelial cells after injury ${ }^{[4]}$. When alveolar epithelial cells are repeatedly stimulated or in a chronic inflammatory environment for a long time, their interaction with lung interstitial cells is enhanced. The recruitment of interstitial cells in the alveolar area leads to extracellular matrix proliferation, alveolar wall thickening, and reduced lung compliance, causing progressive, irreversible damage ${ }^{[5]}$. Persistence of fixed fibrosis accumulation is the final outcome of this pulmonary inflammatory disease ${ }^{[6,7]}$.

Antiviral drugs currently used for lung infections caused by COVID-19, including remdesivir, lopinavirritonavir or lopinavir-ritonavir and interferon (IFN)- $\beta 1^{[8-10]}$. However, they do not halt or reverse the fibrosis that is already established, and the safety and potential efficacy of these drugs is yet to be determined ${ }^{[11}$, ${ }^{12]}$. For this reason, new treatments are needed for this increasingly intractable disease.

With the continuous development of new treatment strategies, cell-based therapies have become a promising option for a variety of diseases ${ }^{[13]}$, including pulmonary fibrosis ${ }^{[14]}$. The most promising treatment is adipose-derived mesenchymal stem cell (MSC) therapy ${ }^{[15,16]}$. Studies have shown that MSCs have immune regulation and tissue repair functions ${ }^{[17,18]}$. MSCs can secrete anti-inflammatory factors, thus reduce the risk of cytokine storm and ARDS, thereby reducing the mortality of severely ill patients ${ }^{[19]}$. Additionally, MSCs can secrete nutritional factors and have multidirectional differentiation ability, allowing them to repair lung tissue damage, prevent and reverse the process of lung fibrosis so as to treat refractory lung injury caused by viral pneumonia ${ }^{[19,20]}$. In this article, we utilize the murine bleomycininduced lung injury model to investigate the effects of MSC therapy on Pulmonary Fibrosis pathology, a disease with prominent features of fibrosis.

\section{Results}

\section{Extraction, differentiation and identification of adipose- derived MSC}

First, we isolated and cultured MSCs from adipose tissue in C57BL/ 6 mice. The adipose tissue from the epididymis of C57BL/ 6 mice was collected in a sterile environment and digested with type I collagenase to remove impurities mature adipocytes. The primary adipose stem cells were obtained and purified by subsequent adherent culture and passage to the third generation ${ }^{[21]}$. The morphology of MSCs gradually changed after the adherent culture and passage, showing a long spindle shape comparable to a fibroblast-like morphology (Fig 1a).

We then used a specific differentiation medium to identify the differentiation ability of the MSCs. In the differentiation into adipocytes experiment, large lipid droplets were seen in the cytoplasm of the induced group, which could be stained with oil red $O$ and then stained red, indicating that the cells could be induced to differentiate into adipocytes. In the osteogenic experiment, the cells were stained with Alizarin 
Red. The induced group changed and light brown calcium nodules were formed, indicating that the MSCs can be induced to differentiate into osteoblasts. In the differentiation into chondrocyte experiment, the cells aggregated into clumps after induction, and were dyed blue-green by Alcian Blue after being sliced, indicating that our MSCs can be induced to differentiate into chondrocytes (Fig 1b).

Finally, we performed flow cytometry analysis on the third-generation MSCs (Fig 1c). CD45 and CD11b antigen/cell marker are negatively expressed; while CD29, CD44, CD90 and other antibodies are positively expressed. This result is in line with the International Cell Association's Identification criteria for the phenotype of adipose-derived MSCs.

\section{Bleomycin promotes lung fibrosis in mice}

We used the murine bleomycin-induced experimental model of pulmonary fibrosis to assess the therapeutic capacity of $\mathrm{MSCs}^{[22]}$. We used bleomycin to model C57BL/ 6 mice by nasal inhalation, with a control group receiving the same amount of PBS solution. Three weeks later, the success of the model was evaluated by gross observation of animal lung tissue, pathological section analysis of lung tissue, and determination of cytokine content. Observing the lung tissues of the two groups in general, the surfaces of the organs in the drug group are smooth, with no lesion or necrosis, while the surface of the tissue and the deep tissue of the control group have a large amount of white spot-like material (Fig 2b).

After the lungs were collected, hematoxylin-eosin (HE) staining was performed (Fig 2c). The alveolar structure of the control group was normal without obvious inflammation or fibrosis. In the drug group, the alveolar structure showed obvious deformation and hyperplasia, the alveolar interval was significantly widened, the alveolar wall of the lung tissue was significantly thickened, the alveolar cavity was edematous and significantly reduced with substantial inflammatory cell infiltration. Masson staining of the lung tissues of the two groups showed that the alveolar structure of the control group was normal without obvious inflammation or fibrosis. In the drug group, the alveolar structure showed severe hyperplasia, with prominent blue collagen fiber deposition. Bleomycin-induced pulmonary fibrosis has a significant increase in collagen deposition (Fig 2d). Accordingly, compared with the control group, animals that received bleomycin presented with a greater Ashcroft score (Fig 2e).

Finally, we extracted genomic RNA from lung tissue to identify the level of related factors. The results are shown in Figure $2 f$, transforming growth factor $\beta$ (TGF- $\beta$ ) and hydroxyproline (HYP; which can indicate the degree of pulmonary fibrosis), Tumor Necrosis Factor a (TNF-a), Interleukin 6 (IL-6) gene expression levels in the drug group were significantly higher than those in the control group. This shows that bleomycin can form a stable pathological state of pulmonary fibrosis (Fig 2f).

\section{MSC therapy reverses bleomycin-induced pulmonary fibrosis}


MSCs were injected into the pulmonary fibrosis animals through the tail vein for treatment. Firstly, the cell fluorescent dyes DAPI and PKH26 were used to stain MSCs to trace the cell's residence in the body. Seven days later, the peripheral blood of the mice was taken for study under a fluorescence microscope. Fluorescently labeled active mesenchymal cells were present in the blood of mice, indicating that MSCs can run with the blood to the whole body (Fig3b).

After 7 and 14 days of injection of MSCs, lung tissues were taken for frozen sections and studied under a fluorescence microscope. MSCs were still present in the lung samples (Fig 3c). This indicates that MSCs can migrate to lung tissue after injection, and therefore are poised to play a therapeutic effect.

Finally, after cell therapy in pulmonary fibrosis mice, lung tissues of different treatment times were selected for Masson staining. The results showed that the collagen content in lung tissues was significantly reduced after cell treatment for one week, and the blue collagen tissues gradually decreased with time after treatment (Fig 3d). This showed that MSCs could significantly reduce the level of collagen deposition in lung tissue, reduce the degree of lung fibrosis, and ultimately repair the biological function of lung tissue. At the same time, animals treated with MSCs gradually showed a lower Ashcroft score (Fig $3 e)$.

Next we studied the expression of lung fibrosis-related factors in both the control group and the therapy group. The gene expression of hydroxyproline (HYP), matrix metalloproteinase-1 (MMP-1) and matrix metalloproteinase-2 (MMP-2) was significantly lower in the treatment group compared to the control group, showing that the presence of MSCs can reverse the pathological state of pulmonary fibrosis and reduce the level of fibrotic lesions (Fig $3 f-h$ ).

\section{Construction of a cellular model of pulmonary fibrosis}

Our studies have shown that MSCs can reverse pulmonary fibrosis in mice. At the same time, we studied the effect of MSCs on pulmonary fibrosis cells at the cellular level. First we obtained a large number of fibroblasts from the lung tissue of newborn C57 mice. (Fig 4b). Subsequently, TGF- $\beta 1$ was used to construct a cellular model of pulmonary fibrosis. After the lung fibroblasts were treated with TGF- $\beta 1$ (10 $\mathrm{mg} \cdot \mathrm{L})$, cell morphology continued to maintain a long spindle-shaped state without aging (Fig 4c).

We then identified whether a pulmonary fibrosis cell model was formed by studying the level of related factors. The results showed that the level of related genes in the TGF- $\beta 1$ group was significantly increased compared to the control group (Fig 4d), including transforming growth factor $\beta 1$ (TGF- $\beta 1$ ), asmooth muscle actin (a-SMA) and type I collagen. However no significant difference was found between the groups in the content of E-cadherin. This outcome shows that the treatment of lung fibroblasts with TGF- $\beta 1$ can cause intracellular collagen deposition and fibrotic changes. 


\section{MSC supernatant promotes the migration and proliferation of fibrotic lung cells in vitro.}

After the successful modelling of lung fibroblasts, the supernatant of MSCs was then used to explore its effect on the proliferation and migration of the lung fibrosis cell model. The results of cell wound healing experiments show that the addition of MSC supernatant can significantly increase the migration level of lung fibrotic cells (Fig 5b). This indicates that the cytokines secreted by MSCs into the supernatant may have a positive effect on fibrotic lung cells.

A transwell experiment was used to explore the effect of MSC supernatant on the migration level of fibrotic lung cells (Fig 5c). After the intervention of MSC supernatant, the number of cells passing through the membrane increased significantly. This shows that MSCs have a certain tropism towards pulmonary fibrotic cells and can promote their migration.

Finally, the CCK-8 experiment was used to explore the effect of MSC supernatant on the proliferation of fibrotic lung cells. As the culture time increased, the addition of MSC supernatant significantly increased the OD value (Fig 5d). Furthermore, MSC supernatant increased cell proliferation in a dose dependent manner (Fig 5d).

\section{MSCs promote the migration and proliferation of lung fibrotic cells in vitro}

We also directly co-cultured MSCs and lung fibrotic cells to explore the effect of MSCs on the biological function of lung fibrotic cells (Fig 6a). The results of cell wound healing experiments showed that, compared with the control group, a co-culture of MSCs and lung fibrotic cells can speed up wound healing (Fig $6 \mathrm{~b}-\mathrm{c}$ ). This may be attributable to the fact that MSC can accelerate the migration rate of lung fibrotic cells.

The results of the Transwell experiment are shown in Figure $6 \mathrm{c} \& \mathrm{~d}$. When the lower chamber contains MSCs, the number of lung fibrotic cells passing through the chamber increases significantly (Fig 6d-e), showing that MSCs can promote the migration level of lung fibrotic cells.

\section{MSC supernatant reduces expression of fibrosis-related genes and protein levels of pulmonary fibrosis cells.}

Finally, we studied the expression levels of pulmonary fibrosis cell-related fibrosis genes and proteins after application of the MSC supernatant.

Firstly, we used qRT-PCR to detect the gene levels of pulmonary fibrosis-related factors. The results showed that the gene levels of TGF- $\beta 1, a-S M A$ and type I collagen in the MSC supernatant treated group 
were significantly lower than those in the control group. This shows that MSC supernatant can change the level of collagen deposition in pulmonary fibrotic cells. This may be related to the active substances secreted by MSCs that improved the fibrosis of the cells (Fig 7b).

Then we detected the protein levels of pulmonary fibrosis-related factors by Western blot. We used high and low concentrations of MSC supernatant to treat lung fibroblasts, and found that the more MSC supernatant, the lower the protein expression levels of TGF- $\beta 1, a-S M A$ and type I collagen. This shows that cytokines and other active substances contained in the MSC supernatant can change the level of collagen deposition in lung fibroblasts and reduce the formation of collagen (Figure 7c-d).

\section{Discussion}

Idiopathic pulmonary fibrosis caused by the 2019 Coronavirus (COVID-19) is a type of pulmonary disease that progresses acutely or slowly into irreversible pulmonary diseases, and can result in severe damage to patients' lung functions, and even death ${ }^{[23-25]}$. At present, the pathogenesis of pulmonary fibrosis is not clear and there is no effective therapeutic measure available to control the progression of the disease ${ }^{[26]}$. Research findings indicate that stem cells play an important role in repairing pulmonary tissue damage ${ }^{[27]}$. Stem cells are attracting growing attention in the field of regenerative medicine, providing new ideas for treating IPF with transplanted stem cells ${ }^{[14]}$. Although there are a wide range of stem cells currently used for IPF treatment, including lung-derived stem cells, bone marrow, fat, placenta and other sources of mesenchymal stem cells, we chose adipose-derived MSC because of its strong differentiation ability, low immunogenicity, and no ethical conflicts. Adipose-derived MSCs have gradually become the "seed cell" in the research of IPF stem cell therapy ${ }^{[16,28]}$.

Here, we successfully isolated and cultured MSCs from adipose tissue with confirmation by reference to previous identification methods ${ }^{[29]}$. C57BL/6 mice were challenged with endotracheal instillation of bleomycin as previously established ${ }^{[30]}$. MSCs were then injected into mice through the tail vein. We found that MSCs reside in the blood of mice for two weeks and can migrate to lung tissues. We demonstrated that a single dose of MSCs effectively reverted core features of bleomycin-induced pulmonary fibrosis, improving pulmonary morphology, blunting collagen deposition, and restoring lung architecture. Previous reports established that MSC/stem cell-based therapies have been effective in preventing experimental models of pulmonary fibrosis ${ }^{[31]}$. Although the findings in this report should be judged in the context of the bleomycin experimental model used, our findings here are consistent with our previous reports showing that MSCs are effective in the treatment of pulmonary fibrosis.

We also studied the effect of MSCs and MSC supernatant on lung fibrotic cells in vitro. Numerous studies have shown that MSCs have a paracrine function and can produce a variety of cytokines that affect cell activity ${ }^{[32,33]}$. Therefore, we used MSC supernatant to interfere with lung fibrotic cells in this study. Interestingly, the results show that MSC supernatant can promote the proliferation and migration of lung fibrotic cells and other biological functions. It also reduces the gene and protein content of collagen fibers 
in pulmonary fibrosis cells in a dose-dependent manner. These results indicate that certain active substances in the MSC supernatant play a role in reversing the fibrosis. Future studies should investigate the precise signaling pathways involved in the paracrine function of MSCs, and which cytokines are involved in this process. Additionally, the effect of MSCs on other cell types in IPF (such as lung epithelial cells and endothelial cells) needs further study.

\section{Conclusion}

In summary, our present study suggests that MSC therapy modulates whole lung inflammation and also demonstrates that MSCs may treat pulmonary fibrosis via their paracrine-related cytokines. However, whether and how theirs cytokines involved in the reversal of fibrosis in lung tissue needs to be further investigated. Collectively or data show that MSC treatment represents a promising cell therapy for the treatment of fibrotic lung diseases.

\section{Materials And Methods}

\section{Bleomycin-induced pulmonary fibrosis model.}

Female or male 8-week-old mice (Shanghai, China) were anesthetized with isoflurane and received a single endotracheal dose of bleomycin sulphate $(50 \mu \mathrm{L}, 3 \mathrm{U} / \mathrm{kg}$ ) at day 0 . Bleomycin naive mice (control) received an endotracheal dose of saline $(50 \mu \mathrm{L})$. Treated animals received a single i.v. (tail vein) dose of MSC (200 $\mu \mathrm{L}$; dose, $\left.5 \times 10^{6} \mathrm{MSCs}\right)$ at day 14 . Control group only (200 $\mu \mathrm{L} ;$ PBS equivalents) served as biological and vehicle controls, respectively. Mice were assessed at day 14 and/or at day 21 or day 28 for cytometric, histological, and/or quantitative PCR (qPCR) analysis. All mice were cared for according to Provisions and General Recommendation of Chinese Experimental Animals Administration Legislation. The procedures for all animal experiments complied with Institutional Animal Care and Use Committee regulations (European Economic Community Council Directive 86/609, 1987).

\section{Isolation and culture of MSCs and lung fibroblasts}

All procedures were carried out in accordance with the guidelines of the Medical Ethics Committee of the Health Bureau. The blood vessels were separated from the fat, cut into $1 \mathrm{~mm}^{3}$ on a cold plate, and then digested in $1 \mathrm{mg} / \mathrm{mL}$ collagenase I (Biosharp, China) at $37^{\circ} \mathrm{C}$ for 0.5 hours to obtain a single cell suspension. Centrifuge the suspension at $2000 \mathrm{rpm}$ for $5 \mathrm{~min}$, and then plant it in a $100 \mathrm{~mm}$ dish. The medium contains Dulbecco's modified Eagle's medium, which contains 10\% FBS, 100 mM non-essential amino acids, and $100 \mathrm{mM}$ sodium pyruvate, $20 \mathrm{mM}$ sodium pyruvate, $\beta$-mercaptoethanol L-glutamine, 20 $\mu \mathrm{g} / \mathrm{mL}$ EGF, $100 \mathrm{IU} / \mathrm{mL}$ penicillin and $100 \mu \mathrm{g} / \mathrm{mL}$ streptomycin (all from Gibco, Carlsbad, CA). After that, MSC was cultured at $37^{\circ} \mathrm{C}$ and $5 \% \mathrm{CO}_{2}$ for about 5 days. When the cells reach $70-80 \%$ confluence, they are harvested with $0.05 \%$ trypsin (Gibco) and subcultured in the same medium. All experiments were performed in the third generation of MSCs. 
The lung tissue was cut into $1 \mathrm{~mm}^{3}$ pieces in a sterile environment, and then placed in a H-glutamine, 20 $\mu \mathrm{g} / \mathrm{mL}$ EGF, $100 \mathrm{IU} / \mathrm{mL}$ penicillin and $100 \mu \mathrm{g} / \mathrm{mL}$ streptomycin (all from Gibco, Carlsbad, CA). After that, Lung fibroblasts was cultured at $37{ }^{\circ} \mathrm{C}$ and $5 \% \mathrm{CO}_{2}$ for about 7 days. When the cells reach $80 \%$ confluence, they are harvested with $0.05 \%$ trypsin (Gibco) and subcultured in the same medium. All experiments were performed in the third generation of fibroblasts.

\section{Flow cytometry analysis}

The International Society for Cellular Therapy (ISCT) has defined that the MSCs can express the surface markers CD29, CD44, CD73, CD90 but lack of expression of CD34, CD45, CD11b ${ }^{[34-36]}$. hUC-MSCs at the third passage were trypsinized and washed twice with PBS and every $1 \times 10^{5}$ cells were stained separately by human monoclonal antibodies CD29-FITC, CD44-FITC, CD90-FITC, CD45-FITC and CD11bFITC (BD Biosciences, Franklin Lakes, $\mathrm{NJ}$ ) at $4{ }^{\circ} \mathrm{C}$ in the dark for $20 \mathrm{~min}$, concomitantly with fluorescein isothiocyanate (FITC) isotype as control. Then the cells were washed and suspended in $500 \mu \mathrm{L}$ of FACS buffer and analyzed by Flow Cytometer (Accuri C6, BD Biosciences).

\section{MSC cell differentiation identification}

To determine the multiple differentiation potentiality of hUC-MSCs, three different induction experiments were utilized. We performed adipogenic, osteogenic and chondrogenic differentiation using the Mesenchymal Stem Cell Functional Identification Kit (R\&D Systems Inc., Minneapolis, MN). The induction processes of the three lineages were performed according to the manufacturer's instructions. The differentiation media was changed every two days. After 10 days, the adipogenic, osteogenic and chondrogenic differentiation were tested by oil red staining, Alizarin Red-S staining and alcian 8GX blue staining (Sigma-Aldrich, St. Louis, MO).

\section{Cell fluorescent labeling}

The MSCs used PKH26 Red Fluorescent Cell Connection Kit (Tanon; Tanon Science \& Technology, Shanghai, China) to stain the cell membrane and DAPI to stain the nucleus. $2 \times 10^{7} \mathrm{MSC}$ cells were Follow the instructions for cell staining. Cell images were captured with a laser scanning confocal microscopy (Olympus, Tokyo, Japan)

\section{RNA extraction and qRT-PCR analysis}

Total RNA was extracted from tissues or cultured cells as previously described ${ }^{[37]}$. Total RNA was extracted by trizol according to kit instructions (Ambion, Foster City, CA). Then cDNA was prepared by AllIn-One RT MasterMix (ABM). Forward and reverse primer sequences used in reverse transcriptase PCR 
(Table 1) were designed by a software Primer 5.0 (PREMIER Biosoft International, Palo Alto, CA), according to the mRNA information of each gene obtained from National Center for Biotechnology Information (NCBI) database. Then real-time PCR was performed using EvaGreen $2 \times$ qPCR MasterMix (ABM) on Light Cycler 480 II (Roche Diagnostics, Basel, Switzerland) by forward and reverse primers.

\section{Western blotting analysis}

A Western blot assay was performed as described ${ }^{[38]}$. Antibodies against TGF- $\beta 1$ (1:5000; Cell Signaling Technology, Danvers, MA, USA), a-SMA (1:5000; Abcam,), and Col $\otimes(1: 5000 ; A b c a m)$ were used as primary antibodies to quantify corresponding proteins by Western blot analysis of whole-cell extracts, which were then detected with horseradish peroxidase-conjugated anti-IgG (1:5000; Santa Cruz Biotechnology, Dallas, TX, USA) and visualized with an enhanced chemiluminescence kit (Tanon; Tanon Science \& Technology, Shanghai, China). Results were normalized with GAPDH (1:2000; Abcam).

\section{In vitro migration of lung fibrotic cells}

To analyze the ability of cells to migrate and invade, wound healing and transwell migration assays were performed, based on previously published methods ${ }^{[37]}$. To assess the migration capability of lung fibrotic cells, cell migration experiments were performed using 24-well transwell plate (PET membrane $8 \mu \mathrm{m}$ pore sizes, Corning Incorporated Costar, Corning, NY). In $200 \mu \mathrm{L}$ serum-free medium, $2 \times 10^{5}$ unloaded and loaded ung fibrotic cells were suspended and seeded in the upper well of the transwell chambers, individually. In each group, one bottom was filled with $600 \mu \mathrm{L} 0.5 \%$ serum medium as control, and the other bottom was filled with $4 \times 10^{5} \mathrm{MSC}$ s suspended in the same medium. After $24 \mathrm{~h}$ incubation, the cells that did not migrate through the pores were removed with a cotton swab. The cells on the lower surface of the membrane were then fixed in methanol for $30 \mathrm{~min}$ and stained with $0.1 \%$ crystal violet for 20 min. Thereafter, each sample was observed by fluorescence inverted microscope (Olympus, Tokyo, Japan) and 10 photographs were captured in a 10-fold objective lens to count the number of stained cells migrating through the membrane pore.

\section{Histology}

Mice were euthanized and their right lungs were embedded in paraffin and sectioned for H\&E or Masson's trichrome staining ${ }^{[39]}$. The left lung was either snap frozen in liquid nitrogen and used for RNA and protein isolation or used fresh for collagen quantification or cytometric analysis. Randomly selected areas (10-15 fields) from 5 - $\mu \mathrm{m}$ thick lung sections were acquired at $\times 100$ and $\times 200$ magnification using a Nikon Eclipse 80i microscope (Nikon). For histologic quantification, the Ashcroft score was used in a blinded fashion ${ }^{[40]}$. Scores of $0-1$ represented no fibrosis, scores of 2-3 represented minimal fibrosis, scores of 4-5 were considered as moderate fibrosis, and scores of 6-8 indicated severe fibrosis. 


\section{Sircol collagen assay}

The left lung was used for collagen quantification per manufacturer's protocol (Bicolor, Life Science Assays) ${ }^{[41]}$. Briefly, left lung homogenate was shaken overnight at $4^{\circ} \mathrm{C}$ in $5 \mathrm{~mL}$ of $0.5 \mathrm{M}$ acetic acid with $0.6 \% \mathrm{v} / \mathrm{v}$ pepsin. A total of $1 \mathrm{~mL}$ of dye reagent was added to $100 \mu \mathrm{L}$ of transparent supernatant, and the samples were vortexed for 30 minutes. The residual pellet was washed by acid-salt wash buffer to eliminate unbound collagen, and $\mathrm{pH}$ was normalized with alkalization buffer. Absorbance was measured at a wavelength of $550 \mathrm{~nm}$ in a microplate reader. Measured collagen content was compared with a standard curve and represented as $\mathrm{mg} / \mathrm{mL}$ of left lung homogenate.

\section{Statistical analysis}

All experimental data were expressed as the means \pm sd. Statistical analysis was performed using the Student's independent $t$ test via Prism 9 software (GraphPad Software, La Jolla, CA, USA) between

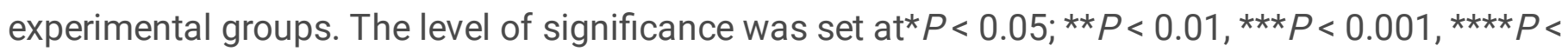
0.0001 .

\section{Abbreviations}

IPF: Idiopathic pulmonary fibrosis; SVF: Stromal vascular fraction; MSC: Mesenchymal stromal/stem cell;ARDS: Acute respiratory distress syndrome;

\section{Declarations}

\section{Acknowledgements}

Not applicable.

\section{Funding}

This work was supported by 1) Science and Technology Innovation Action Plan of Shanghai Science and Technology Commission (Project No 19441909900); 2) Strategic Priority Research Program of the Chinese Academy of Sciences Grant No. XDA* (XDA16040400).

\section{Authors' contributions}

$X Z$ : study design, experiment/analysis performance, protocol optimization, data analysis, manuscript writing and revision; JW: study design, protocol optimization, data collection, manuscript revision; RY, YL, QY, BW, XZ, JW JM and WZ: data collection, manuscript revision; All authors read and approved the final manuscript; NZ: study design, manuscript revision and approval. 


\section{Availability of data and materials}

The datasets generated during and/or analyzed during the current study are available from the corresponding author on reasonable request

\section{Ethics approval and consent to participate}

The study was conducted along the guidelines set by the Ethics Committee of Shanghai Jiaotong University School of Medicine, Shanghai, China

\section{Consent for publication}

Not applicable

\section{Availability of data and material}

Not applicable

\section{Competing interests}

The authors declare no conflict of interest, financial or otherwise.

\section{References}

1. ZHU N, ZHANG D, WANG W, et al. A Novel Coronavirus from Patients with Pneumonia in China, 2019 [J]. N Engl J Med. 2020;382(8):727-33.

2. SHEAHAN T P, SIMS A C, LEIST S R, et al. Comparative therapeutic efficacy of remdesivir and combination lopinavir, ritonavir, and interferon beta against MERS-CoV [J]. Nat Commun. 2020;11(1):222.

3. BROOKS PJ, SAMUEL L T, LEVIN JM, et al. Mortality after hip resurfacing versus total hip arthroplasty in young patients: a single surgeon experience [J]. Ann Transl Med. 2019;7(4):77.

4. BLOKLAND K E C, WATERS D W, SCHULIGA M, et al. Senescence of IPF Lung Fibroblasts Disrupt Alveolar Epithelial Cell Proliferation and Promote Migration in Wound Healing [J]. Pharmaceutics, 2020, 12(4).

5. FERNANDEZ I E EICKELBERGO. New cellular and molecular mechanisms of lung injury and fibrosis in idiopathic pulmonary fibrosis [J]. Lancet. 2012;380(9842):680-8. 
6. KOMATSU M, YAMAMOTO H, KITAGUCHI Y, et al. Clinical characteristics of non-idiopathic pulmonary fibrosis, progressive fibrosing interstitial lung diseases: A single-center retrospective study [J]. Med (Baltim). 2021;100(13):e25322.

7. LIU M, REN D, WU D, et al. Stem Cell and Idiopathic Pulmonary Fibrosis: Mechanisms and Treatment [J]. Curr Stem Cell Res Ther. 2015;10(6):466-76.

8. CAO B, WANG Y, WEN D, et al. A Trial of Lopinavir-Ritonavir in Adults Hospitalized with Severe Covid19 [J]. N Engl J Med. 2020;382(19):1787-99.

9. CHU C M, CHENG V C, HUNG I F, et al. Role of lopinavir/ritonavir in the treatment of SARS: initial virological and clinical findings [J]. Thorax. 2004;59(3):252-6.

10. GROUP R C. Lopinavir-ritonavir in patients admitted to hospital with COVID-19 (RECOVERY): a randomised, controlled, open-label, platform trial [J]. Lancet, 2020.

11. GARVIN M R, ALVAREZ C, MILLER J I, et al. A mechanistic model and therapeutic interventions for COVID-19 involving a RAS-mediated bradykinin storm [J]. Elife, 2020, 9.

12. NASTASE M V, ZENG-BROUWERS J, WYGRECKA M, et al. Targeting renal fibrosis: Mechanisms and drug delivery systems [J]. Adv Drug Deliv Rev. 2018;129:295-307.

13. RAFFIN C, VO L T, BLUESTONE JA. Treg cell-based therapies: challenges and perspectives [J]. Nat Rev Immunol. 2020;20(3):158-72.

14. GLASSBERG M K, MINKIEWICZ J, TOONKEL R L, et al. Allogeneic Human Mesenchymal Stem Cells in Patients With Idiopathic Pulmonary Fibrosis via Intravenous Delivery (AETHER): A Phase I Safety Clinical Trial [J]. Chest. 2017;151(5):971-81.

15. KHOURY M, CUENCA J, CRUZ F F, et al. Current status of cell-based therapies for respiratory virus infections: applicability to COVID-19 [J]. Eur Respir J, 2020, 55(6).

16. CHEN S, CUI G, PENG C, et al. Transplantation of adipose-derived mesenchymal stem cells attenuates pulmonary fibrosis of silicosis via anti-inflammatory and anti-apoptosis effects in rats [J]. Stem Cell Res Ther. 2018;9(1):110.

17. HU S, PARK J, LIU A, et al. Mesenchymal Stem Cell Microvesicles Restore Protein Permeability Across Primary Cultures of Injured Human Lung Microvascular Endothelial Cells [J]. Stem Cells Transl Med. 2018;7(8):615-24.

18. LEE JW, MCKENNA D H KRASNODEMBSKAYAA, et al. Therapeutic effects of human mesenchymal stem cells in ex vivo human lungs injured with live bacteria [J]. Am J Respir Crit Care Med. 2013;187(7):751-60.

19. LAFFEY J G, MATTHAY MA. Fifty Years of Research in ARDS. Cell-based Therapy for Acute Respiratory Distress Syndrome. Biology and Potential Therapeutic Value [J]. Am J Respir Crit Care Med. 2017;196(3):266-73.

20. COURT A C, LE-GATT A, LUZ-CRAWFORD P, et al. Mitochondrial transfer from MSCs to T cells induces Treg differentiation and restricts inflammatory response [J]. EMBO Rep. 2020;21(2):e48052. 
21. LIN K, MATSUBARA Y, MASUDA Y, et al. Characterization of adipose tissue-derived cells isolated with the Celution system [J]. Cytotherapy. 2008;10(4):417-26.

22. MOELLER A, ASK K, WARBURTON D, et al. The bleomycin animal model: a useful tool to investigate treatment options for idiopathic pulmonary fibrosis? [J]. Int J Biochem Cell Biol. 2008;40(3):362-82.

23. GEORGE P M, WELLS A U, JENKINS RG. Pulmonary fibrosis and COVID-19: the potential role for antifibrotic therapy [J]. Lancet Respir Med. 2020;8(8):807-15.

24. Overwhelming AKRAMA. COVID-19 Sepsis in a Patient With Idiopathic Pulmonary Fibrosis [J]. Cureus. 2020;12(7):e9320.

25. MISHRA M. SINDHWANI G. Antifibrotics for COVID-19 related lung fibrosis: Agents with benefits? [J]. Adv Respir Med. 2021;89(2):231-3.

26. WYNN T A. Integrating mechanisms of pulmonary fibrosis [J]. J Exp Med. 2011;208(7):1339-50.

27. SUN Y, SHI H. YIN S, et al. Human Mesenchymal Stem Cell Derived Exosomes Alleviate Type 2 Diabetes Mellitus by Reversing Peripheral Insulin Resistance and Relieving beta-Cell Destruction [J]. ACS Nano. 2018;12(8):7613-28.

28. REDDY M, FONSECA L, GOWDA S, et al. Human Adipose-derived Mesenchymal Stem Cells Attenuate Early Stage of Bleomycin Induced Pulmonary Fibrosis: Comparison with Pirfenidone [J]. Int J Stem Cells. 2016;9(2):192-206.

29. TASSI SA, SERGIO N Z, MISAWA M Y O, et al. Efficacy of stem cells on periodontal regeneration: Systematic review of pre-clinical studies [J]. J Periodontal Res. 2017;52(5):793-812.

30. SONG X, YU W, GUO F. Pirfenidone suppresses bleomycin-induced pulmonary fibrosis and periostin expression in rats [J]. Exp Ther Med. 2018;16(3):1800-6.

31. GHADIRI M, YOUNG P M TRAINID. Cell-based therapies for the treatment of idiopathic pulmonary fibrosis (IPF) disease [J]. Expert Opin Biol Ther. 2016;16(3):375-87.

32. KESHTKAR S, AZARPIRA N, GHAHREMANI MH. Mesenchymal stem cell-derived extracellular vesicles: novel frontiers in regenerative medicine [J]. Stem Cell Res Ther. 2018;9(1):63.

33. ANDRZEJEWSKA A, LUKOMSKA B. JANOWSKI M. Concise Review: Mesenchymal Stem Cells: From Roots to Boost [J]. Stem Cells. 2019;37(7):855-64.

34. PITTENGER M F, MACKAY A M, BECK S C, et al. Multilineage potential of adult human mesenchymal stem cells [J]. Science. 1999;284(5411):143-7.

35. DOMINICI M, LE BLANC K, MUELLER I, et al. Minimal criteria for defining multipotent mesenchymal stromal cells. The International Society for Cellular Therapy position statement [J]. Cytotherapy. 2006;8(4):315-7.

36. BOURIN P, BUNNELL B A CASTEILLAL, et al. Stromal cells from the adipose tissue-derived stromal vascular fraction and culture expanded adipose tissue-derived stromal/stem cells: a joint statement of the International Federation for Adipose Therapeutics and Science (IFATS) and the International Society for Cellular Therapy (ISCT) [J]. Cytotherapy. 2013;15(6):641-8. 
37. LIU X, FENG J, ZHANG Q, et al. Analytical comparisons of SARS-COV-2 detection by qRT-PCR and ddPCR with multiple primer/probe sets [J]. Emerg Microbes Infect. 2020;9(1):1175-9.

38. BASS JJ, WILKINSON D J, RANKIN D, et al. An overview of technical considerations for Western blotting applications to physiological research [J]. Scand J Med Sci Sports. 2017;27(1):4-25.

39. CANFIELD PJ, HEMSLEY S. The roles of histology and immunohistology in the investigation of marsupial disease and normal lymphoid tissue [J]. Dev Comp Immunol. 2000;24(5):455-71.

40. LIX, DUAN L, YUAN S, et al. Ferroptosis inhibitor alleviates Radiation-induced lung fibrosis (RILF) via down-regulation of TGF-beta1 [J]. J Inflamm (Lond), 2019, 16(11.

41. LAREU R R, ZEUGOLIS D I, ABU-RUB M, et al. Essential modification of the Sircol Collagen Assay for the accurate quantification of collagen content in complex protein solutions [J]. Acta Biomater. 2010;6(8):3146-51.

\section{Table}

Table 1 is not available with this version.

\section{Figures}




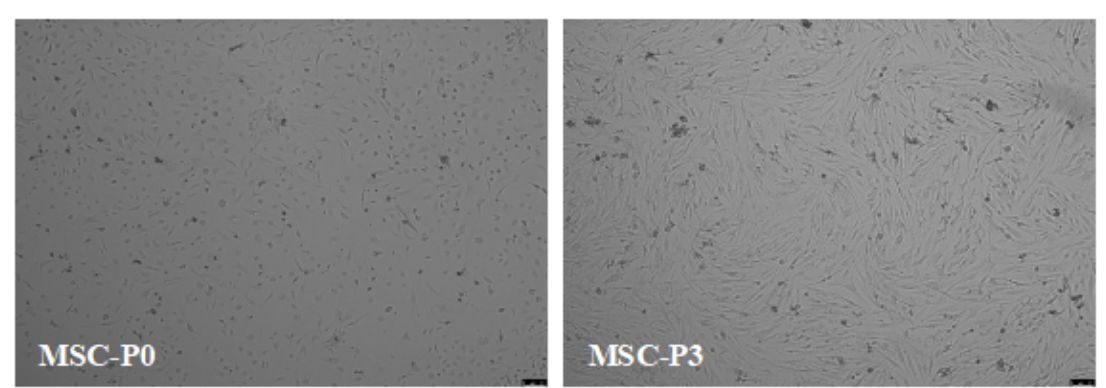

b
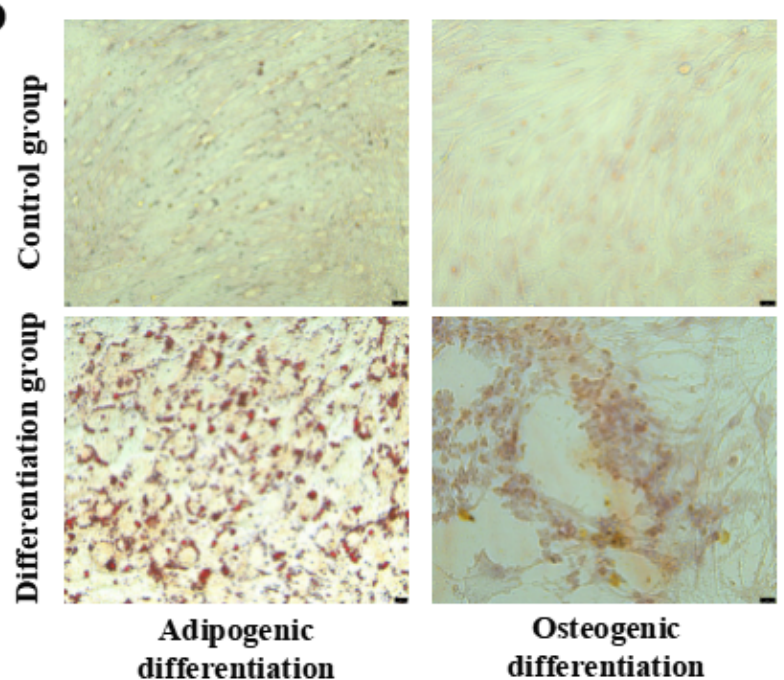

Osteogenic

differentiation

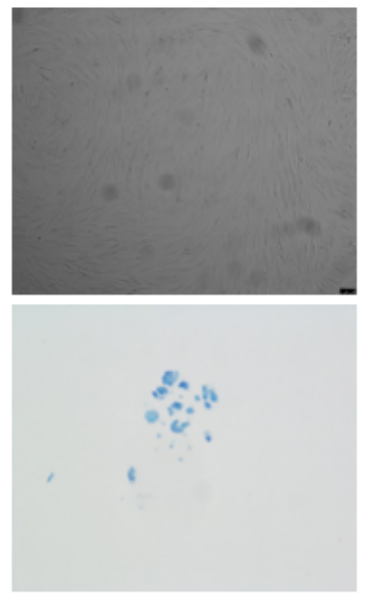

Chondrogenic differentiation

c
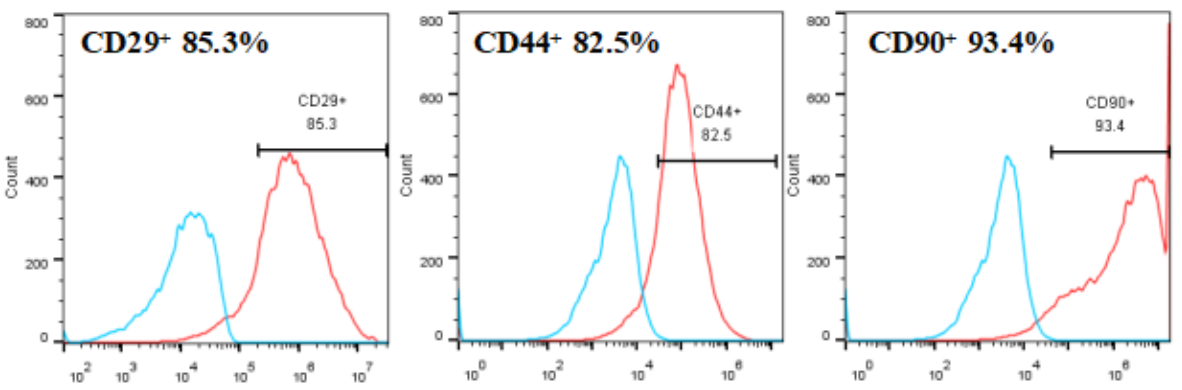

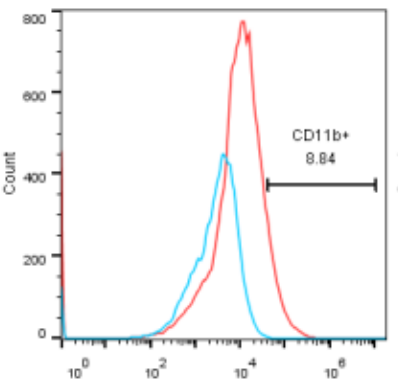

CD11b 8.84\%

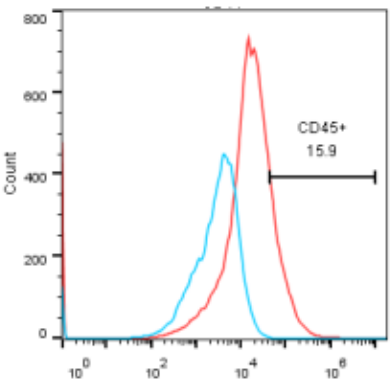

$\mathrm{CD}^{4}{ }^{+}{ }^{15.9 \%}$

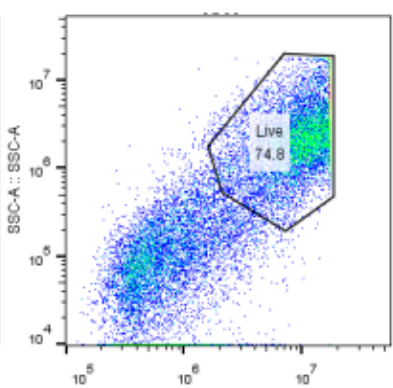

Live cell $74.8 \%$

\section{Figure 1}

Cultivation, differentiation and identification of MSCs. (a)Morphology of MSCs under different culture passages, the first-generation MSCs are generally triangular or dot-shaped,and the third-generation MSCs generally form spindles or are elongated. Images were taken at $\times 40$ magnification. (b) MSCs undergo different staining treatments after differentiation. They were successfully differentiated into adipocytes (stained red with Oil Red), osteoblasts (stained with Alizarin Red) and chondrocytes (stained with Alcian 
Blue). Scale bar $=100 \mu \mathrm{m}$ Images were taken at $\times 100$ magnification. (c) Flow cytometric analysis of MSCs after 3 passages of culture showed that CD 45 and CD11b antigen/cell markers are negatively expressed, while CD29, CD44, CD90 and other antibodies are positively expressed, Student's t test (2 tailed).

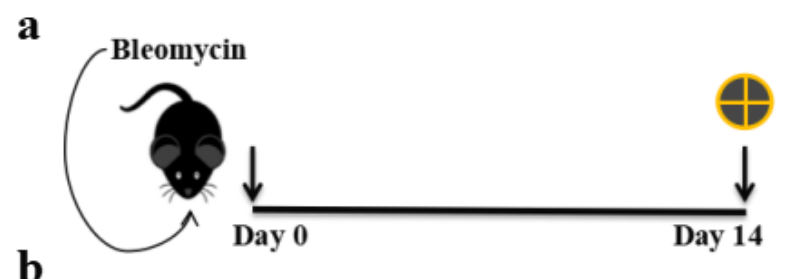

b
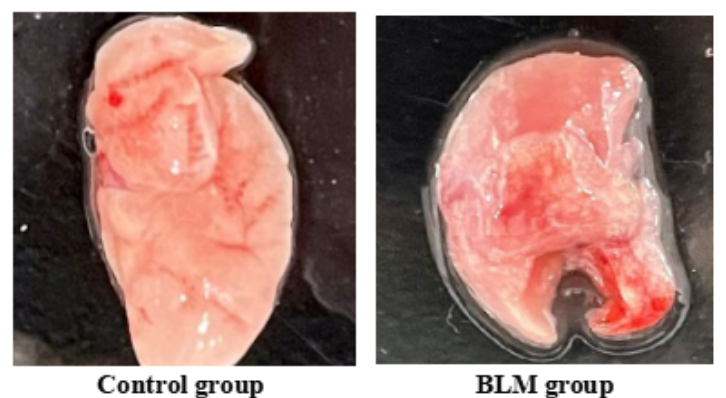

c
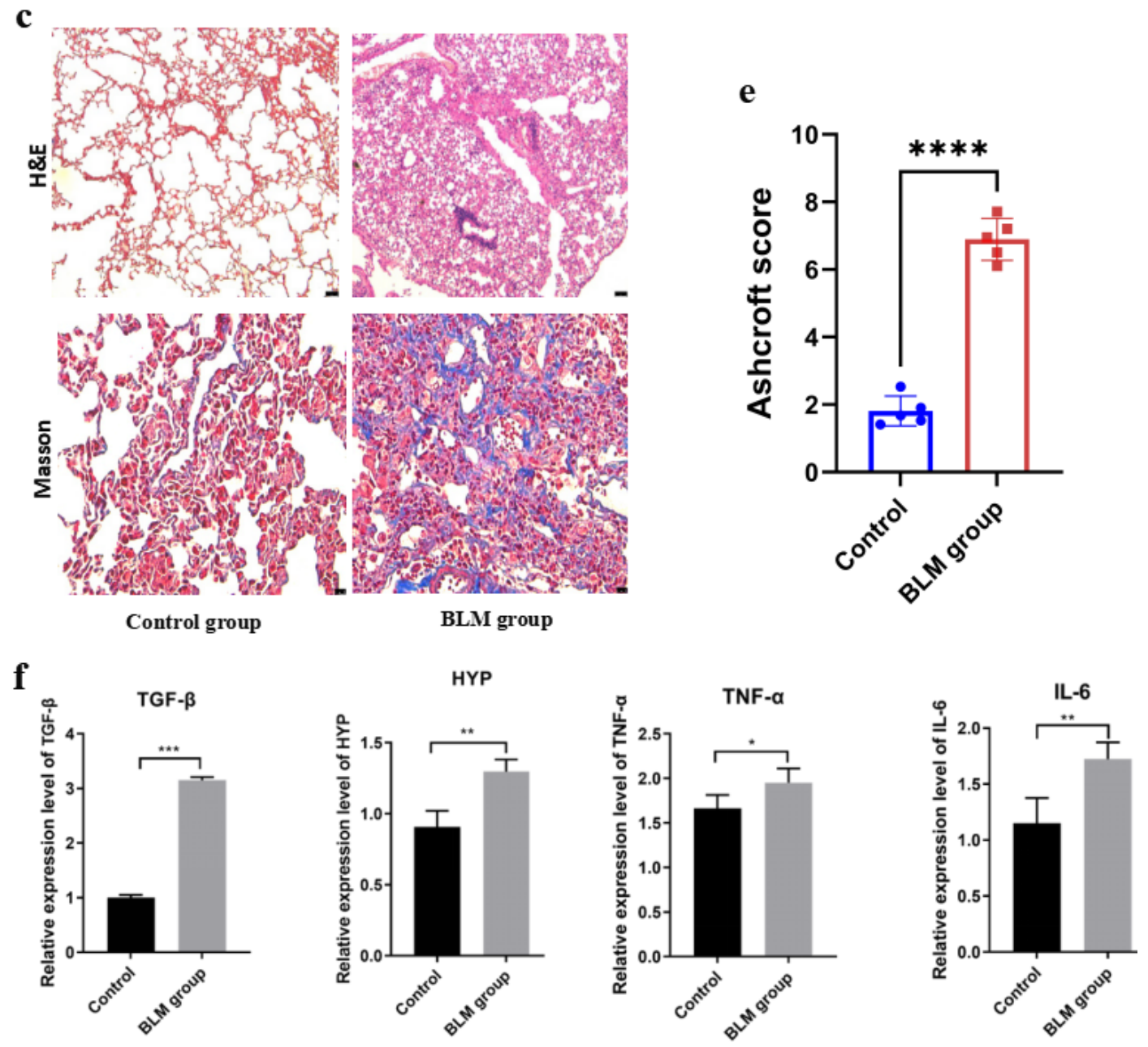

d

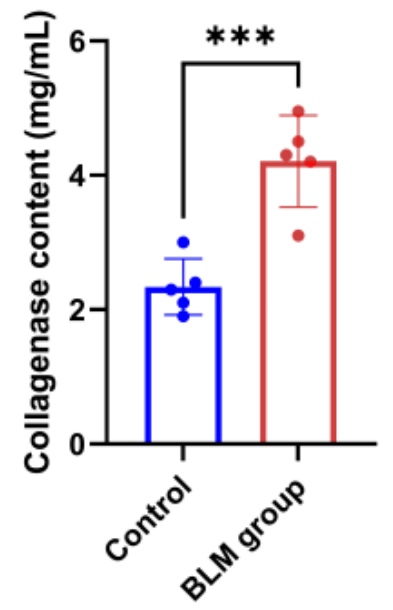

e

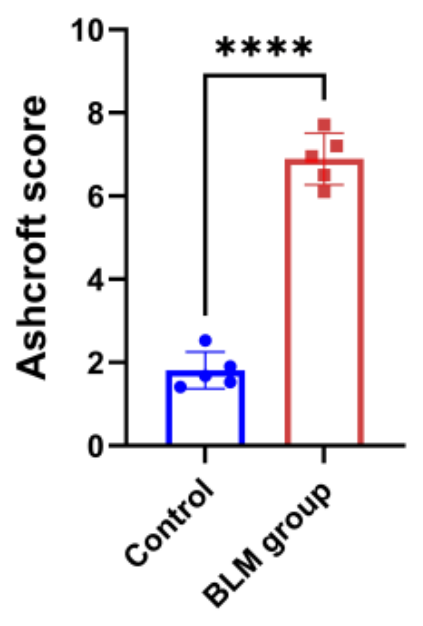

Figure 2 
Bleomycin-induced pulmonary fibrosis mouse model. (a) Eight-week-old mice (C57BL/ 6 strain) received endotracheal bleomycin $(3 \mathrm{U} / \mathrm{kg}$ ) or $0.9 \%$ normal saline on day 0 (control). Mice were sacrificed on day 14. The cross symbol represents animal harvest. (b) Observation of mouse lung tissue. (c) Lung sections were stained with Hematoxylin-eosin and Masson's trichrome. Images were taken at $\times 100$ magnification. Bleomycin group showed architectural destruction, alveolar septal thickening, and fibrotic changes. Scale bar: $100 \mu \mathrm{m}$. (d) Collagen deposition was assessed by Sircol assay and represent-ed as $\mathrm{mg} / \mathrm{mL}$ of left lung homogenate. (e) Lung fibrosis was measured at day 14 by Ashcroft score. (f) qRT-PCR analysis of bleomycin induces changes in the expression of pulmonary fibrosis-related genes. The mice were sacrificed humanely, and lung tissues were collected to assess the mRNA levels of fibrosis-related genes. Expression of TGF- $\beta \square$ HYP $T$ TNF-a $\square$ and IL- 6 levels ( $n=6$ mice per group). Data are representative of 5 independent experiments, mean $\pm S D$. $n=5$ per experimental group; each symbol represents 1 mouse. *P $<0.05 ;{ }^{* \star} \mathrm{P}<0.01,{ }^{\star \star \star} \mathrm{P}<0.001,{ }^{\star \star \star \star} \mathrm{P}<0.0001,1$-way ANOVA followed by Fisher's LSD post hoc analysis. 


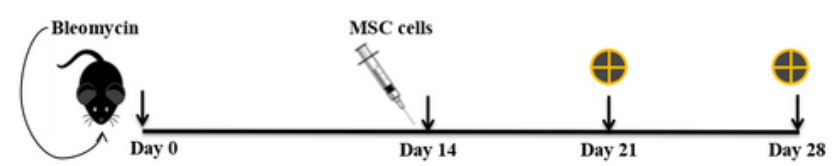

b
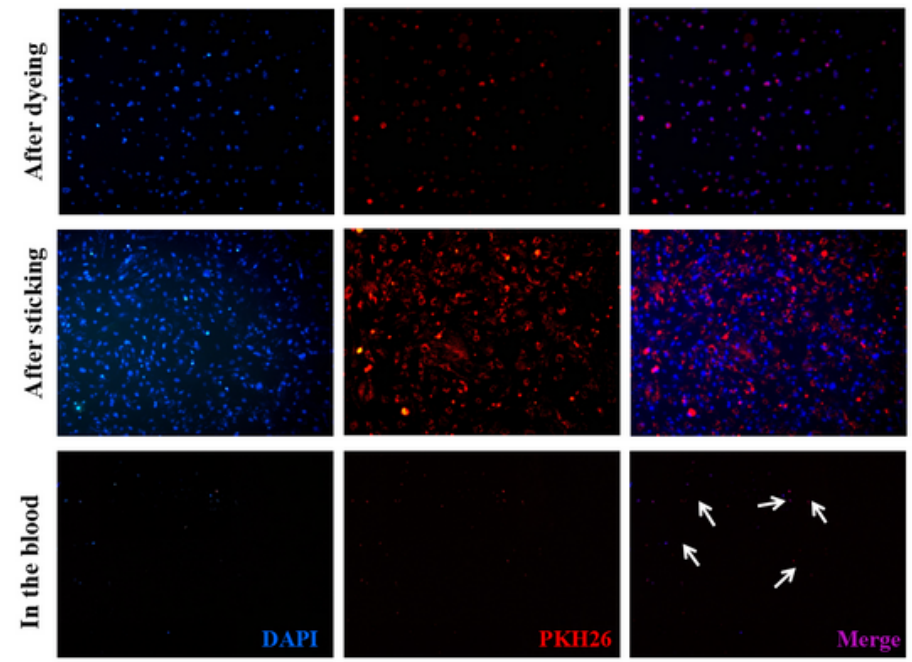

c
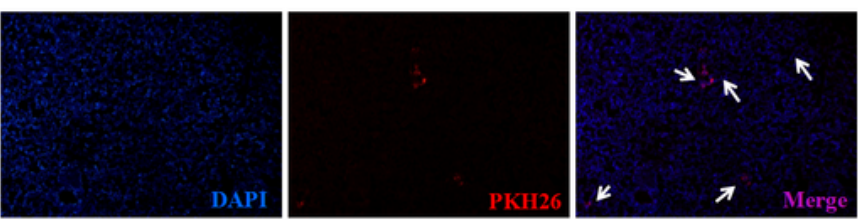

d
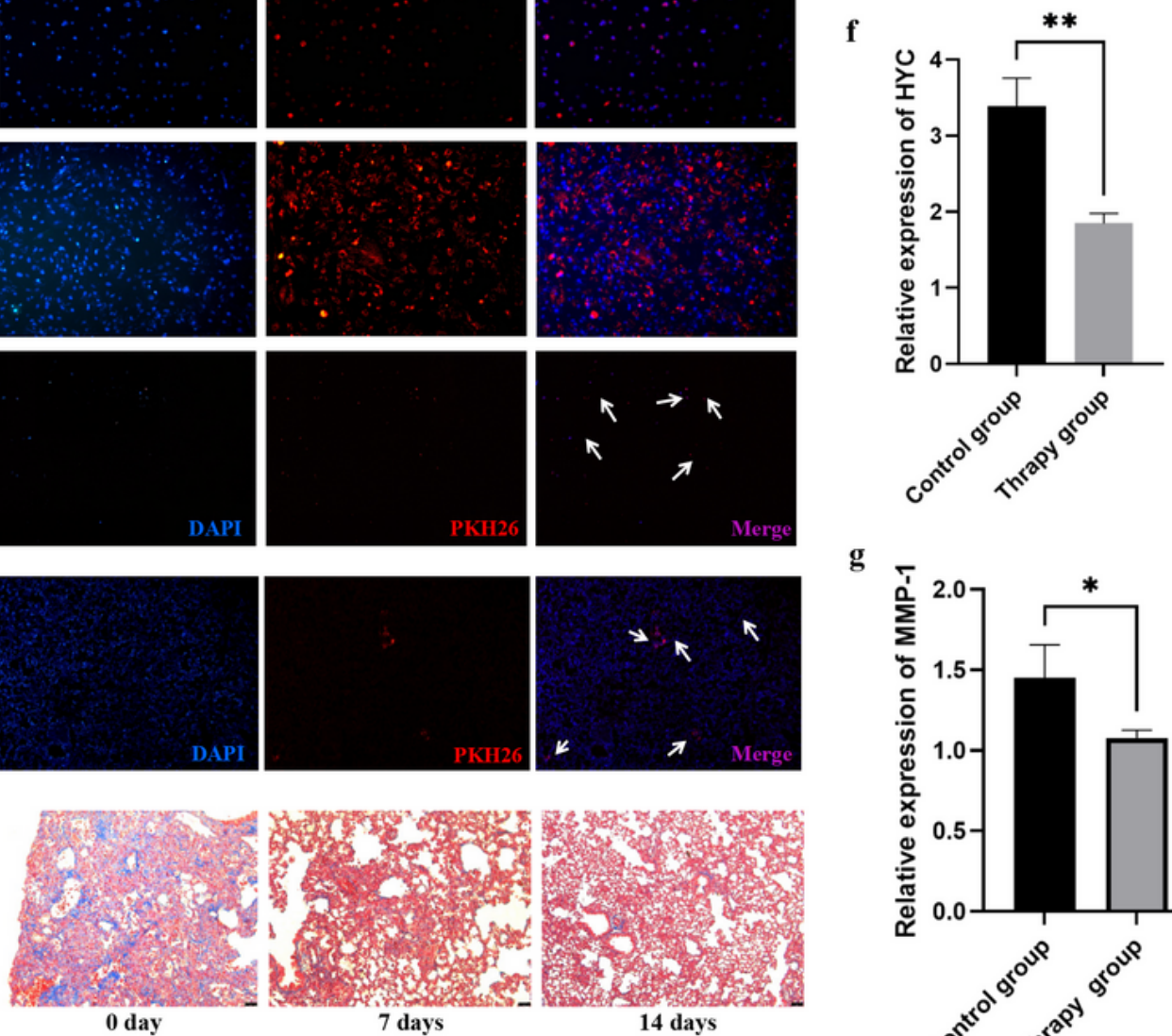

g

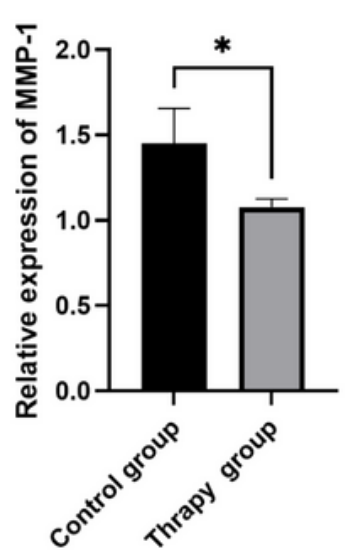

e
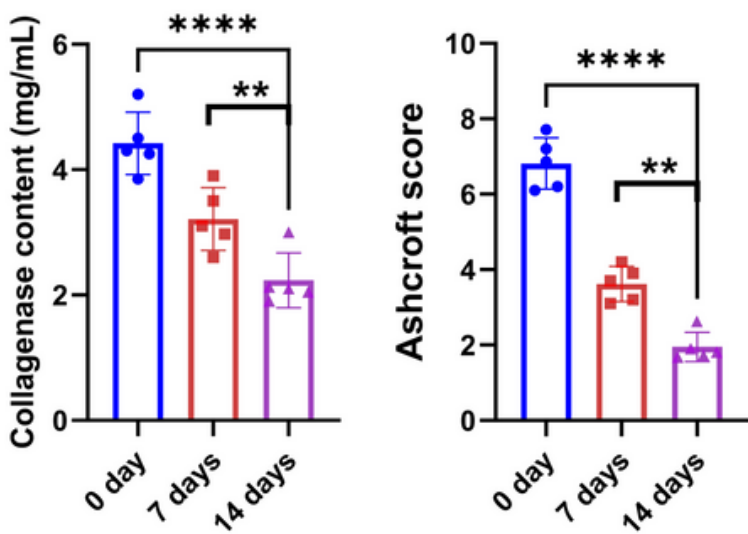

h

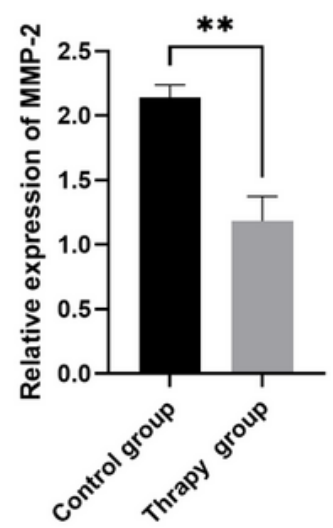

Figure 3

MSC therapy reverts bleomycin-induced pulmonary fibrosis. (a) MSCs were administered 14 days after the administration of bleomycin, and mice were sacrificed on day 21 or 28. Cross symbol represents animal harvest. (b) MSCs were stained with fluorescent dyes, DAPI for the nucleus, and PKH26 for the cell membrane. After the mice were sacrificed, fluorescently labeled MSCs could be detected in their peripheral blood. (c) Lung slices are used for fluorescence microscopy. The image was taken at $\times 100$ 
magnification. Fluorescently labeled MSCs can be observed after cell therapy. (d) Lung sections were stained with Mason's trichrome. The image was taken at $\times 100$ magnification. Collagen deposition decreased in a time dependent fashion following MSC therapy. Scale bar: $100 \mu \mathrm{m}$. (e) Collagen deposition was assessed by Sircol assay and represent-ed as $\mathrm{mg} / \mathrm{mL}$ of left lung homogenate. Lung fibrosis was measured at day 0,7 and 14 by Ashcroft score. (f-h) qRT-PCR analysis of gene expression of related cytokines in lung tissue after MSC cell therapy. The mice were sacrificed humanely, and lung tissues were collected to assess the mRNA levels of fibrosis-related genes. Expression of HYP and MMP-2 levels ( $n=6$ mice per group). Data are representative of 5 independent experiments, mean \pm SD. $n=5$ per experimental group; each symbol represents 1 mouse. ${ }^{*} P<0.05 ; * \star P<0.01$, ${ }^{\star \star \star} P<0.001$, $\star \star \star \star * P<0.0001,1$-way ANOVA followed by Fisher's Dunnett post hoc analysis. 


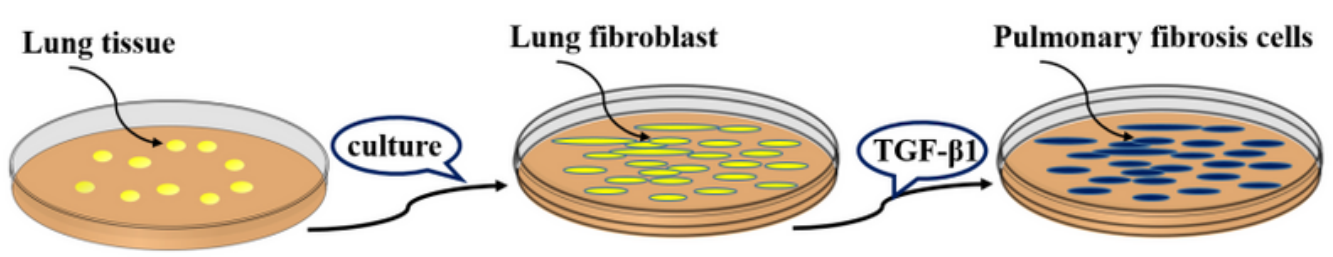

b

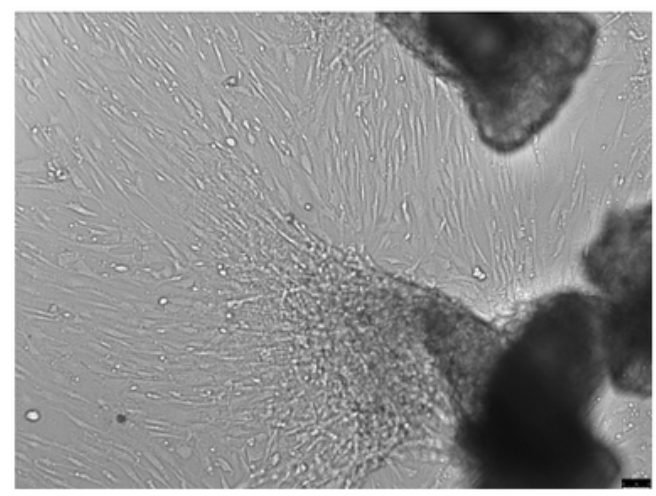

P0

c

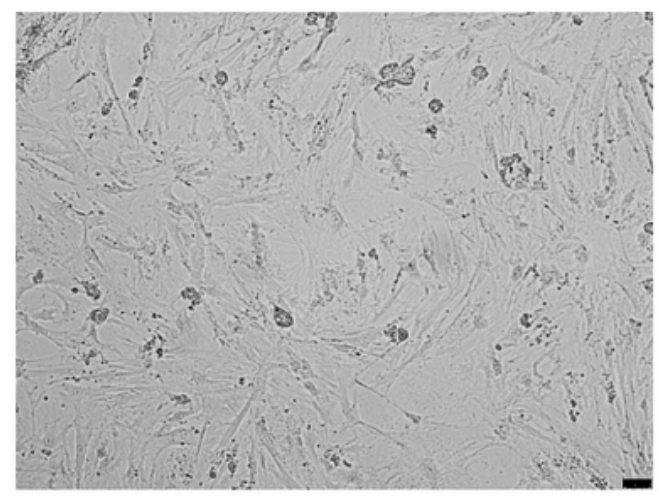

Control group

d
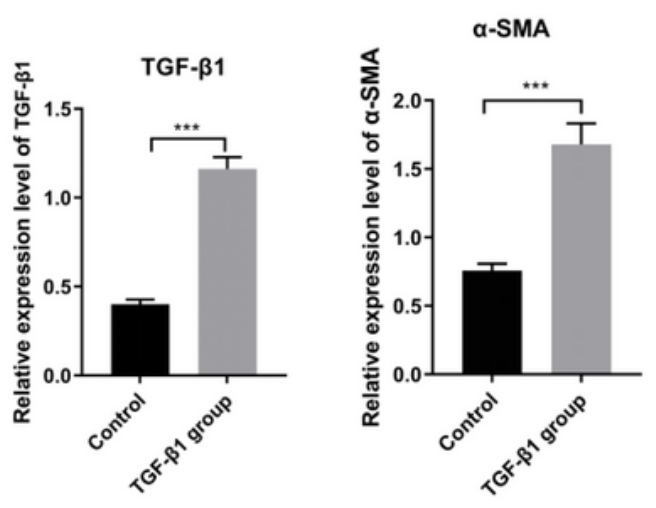

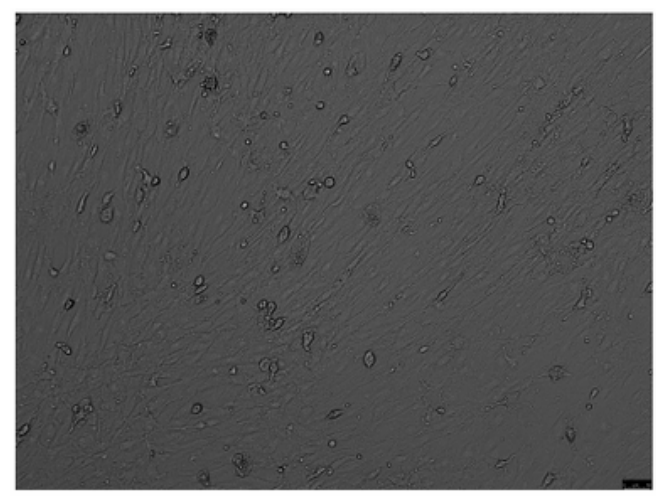

P1

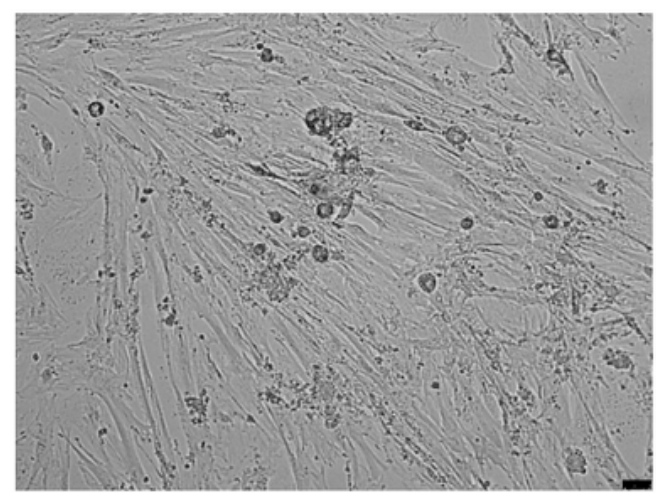

TGF-ק1 group
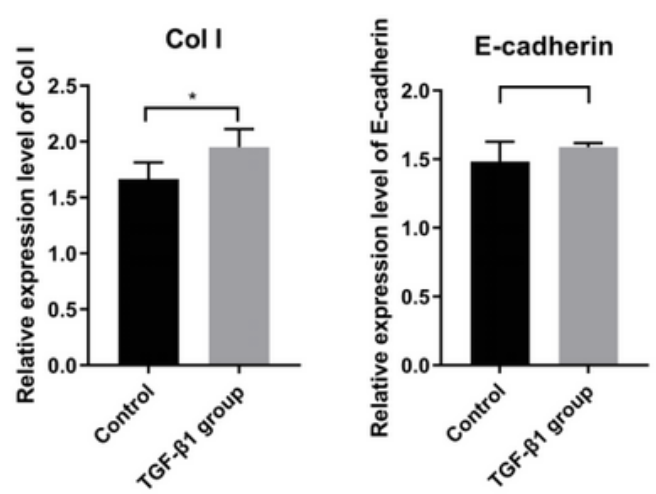

\section{Figure 4}

Cellular model of pulmonary fibrosis induced by TGF- $\beta 1$. (a) Pulmonary fibroblasts were obtained from lung tissue through an adherent culture, and then TGF- $\beta 1$ was used to induce them into pulmonary fibrotic cells. (b) Pulmonary fibroblasts were purified from lung tissue and cultured for cell passage. Images were taken at $\times 40$ magnification. Scale bar: $100 \mu \mathrm{m}$. (c) Lung fibroblasts were induced by TGF- $\beta 1$ $(10 \mathrm{mg} \cdot \mathrm{L})$. Images were taken at $\times 100$ magnification. Scale bar: $100 \mu \mathrm{m}$. (d) qRT-PCR analysis of gene 
expression supports formation of a cellular model of pulmonary fibrosis following induction by TGF- $\beta 1$. Expression of TGF- $\beta 1 \square a-S M A \square C o l ~ \otimes$ and E-cadherin levels ( $n=3$ per group). Data are representative of 5 independent experiments, mean \pm SD. $n=5$ per experimental group. ${ }^{*} P<0.05 ; * * P<0.01$, ${ }^{\star * *} P<0.001,1$ way ANOVA followed by Fisher's LSD post hoc analysis.

a

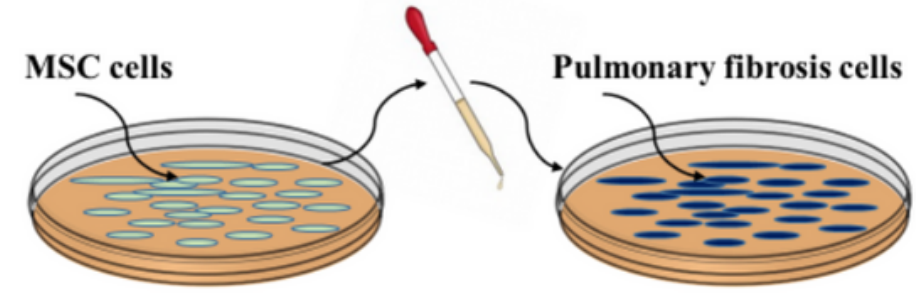

b

Oh

24h

$48 h$
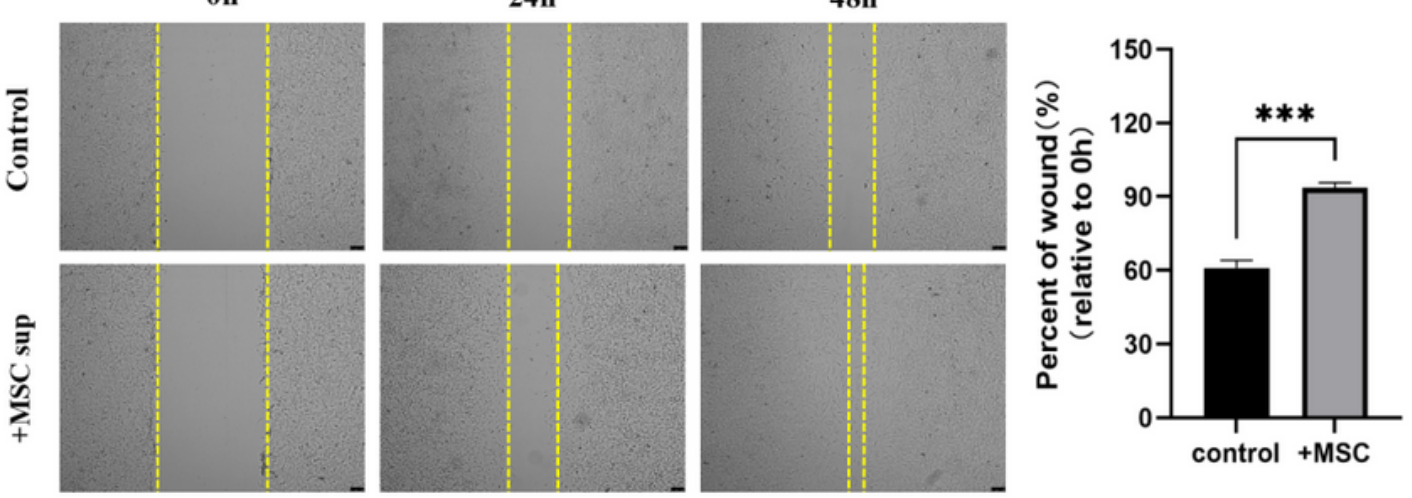

c
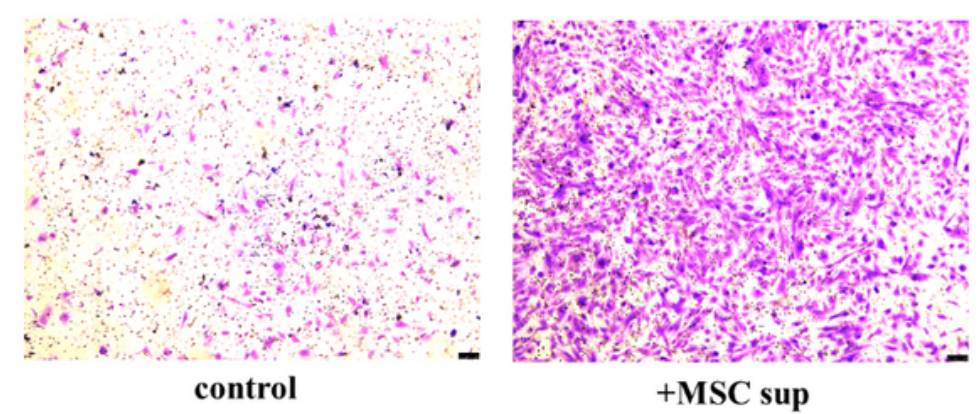

d
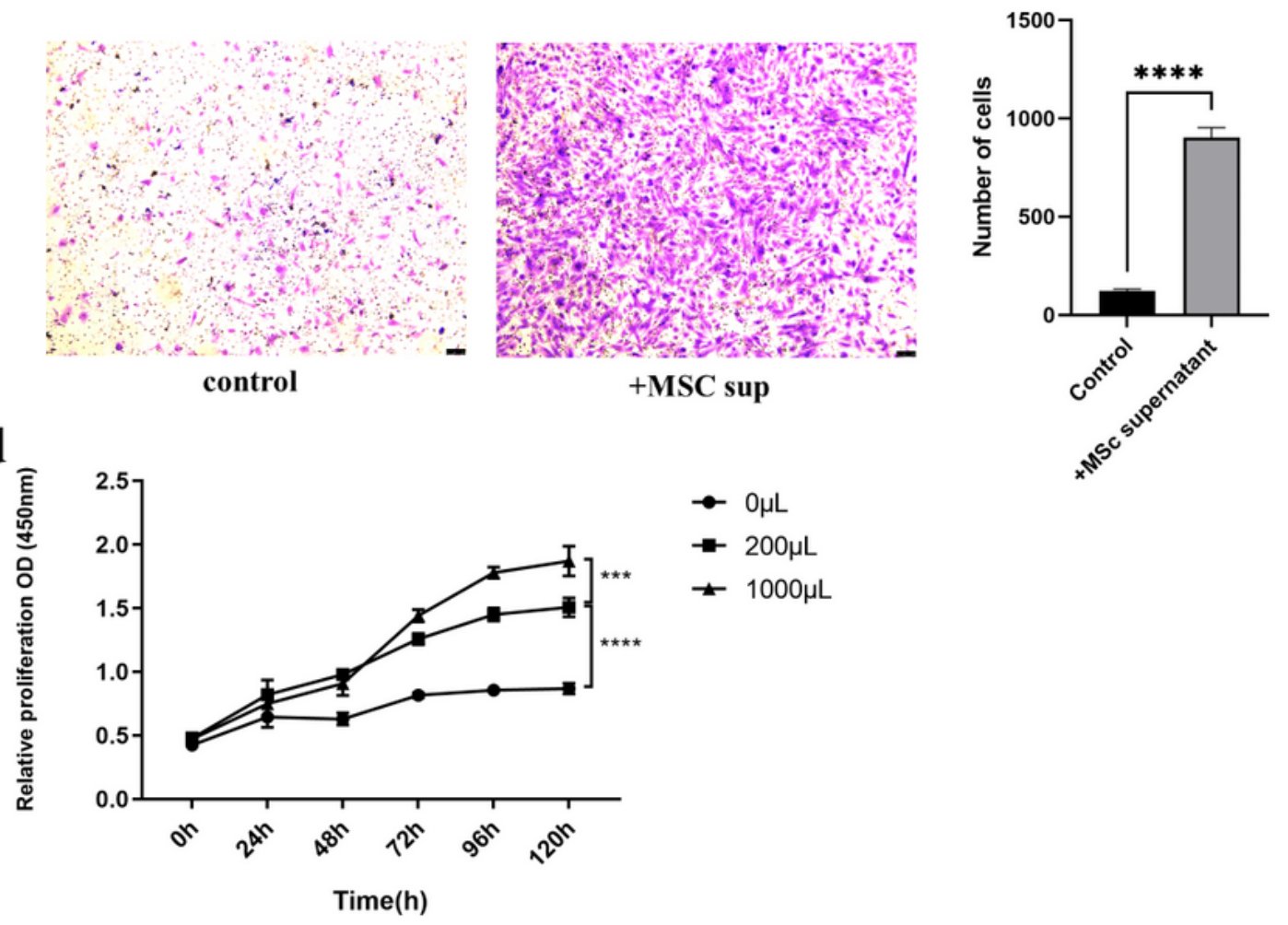

Figure 5 
MSC supernatant promotes the migration and proliferation of fibrotic lung cells in vitro. (a) MSC supernatant was harvested and added to the culture medium of lung fibrosis cells. (b) Our wound healing experiment detected the migration level of lung fibrotic cells after adding MSC supernatant. (c) The transwell migration assay method detects the migration level of lung fibrotic cells after adding MSC supernatant. (d) The CCK-8 viability assay of the lung fibrotic cells added to the MSC supernatant. All results are represented as mean $\pm S D$. $n=5$ per experimental group. ${ }^{\star} * \star P<0.001, * \star \star \star P<0.0001,2$-way ANOVA followed by Fisher's Dunnett post hoc analysis.

$\mathbf{a}$
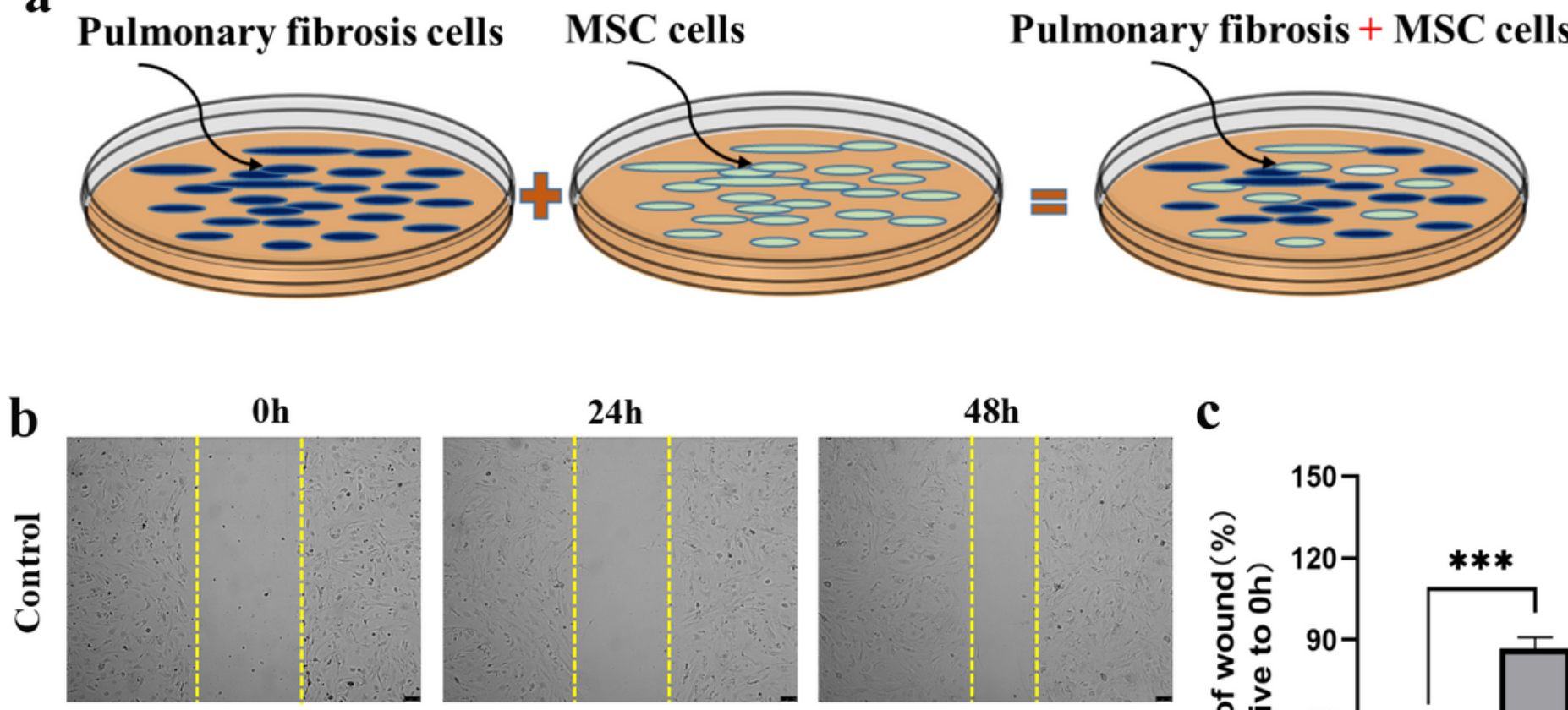

C
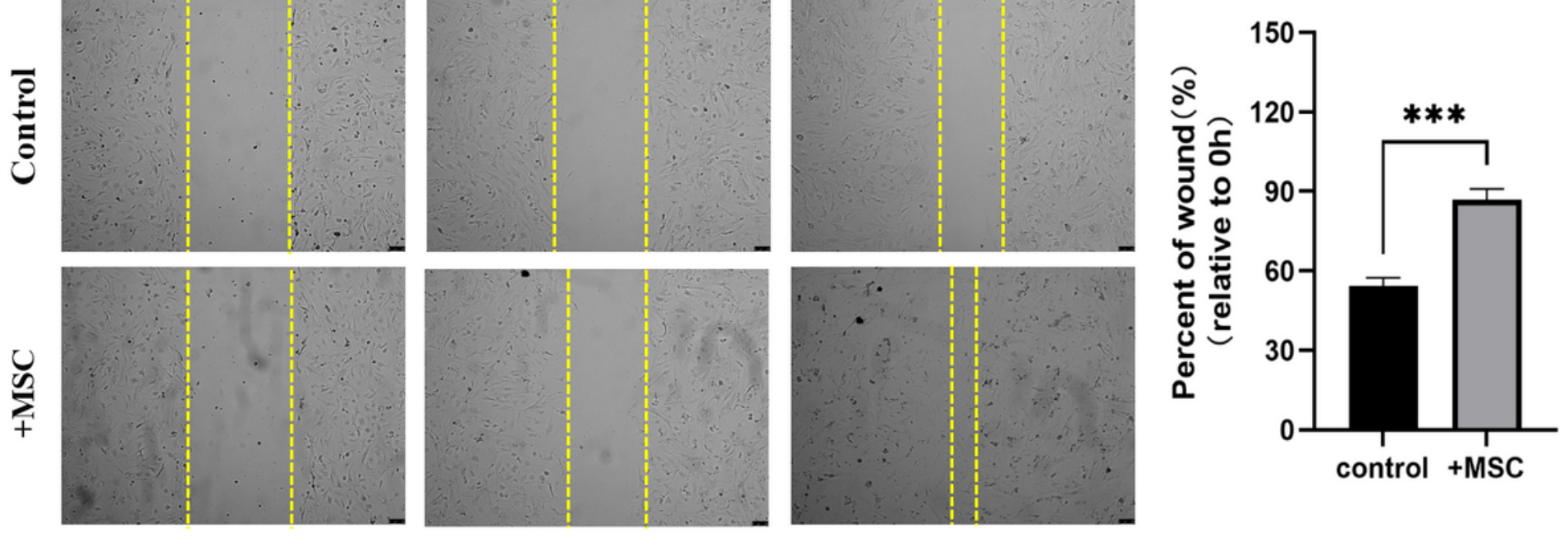

d

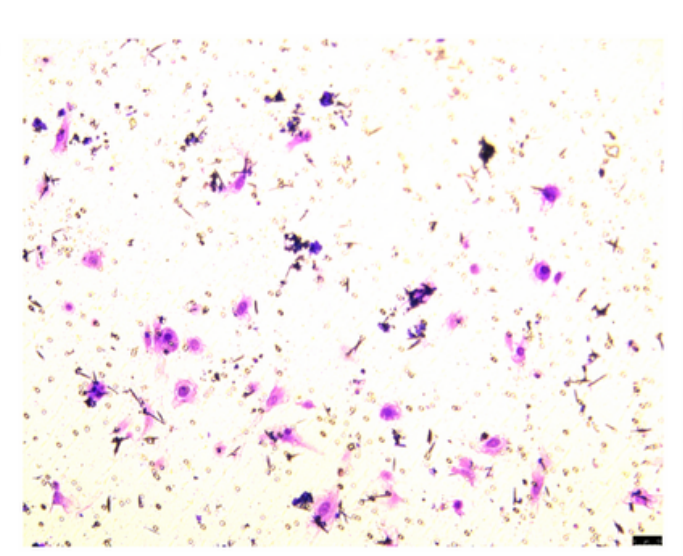

Control

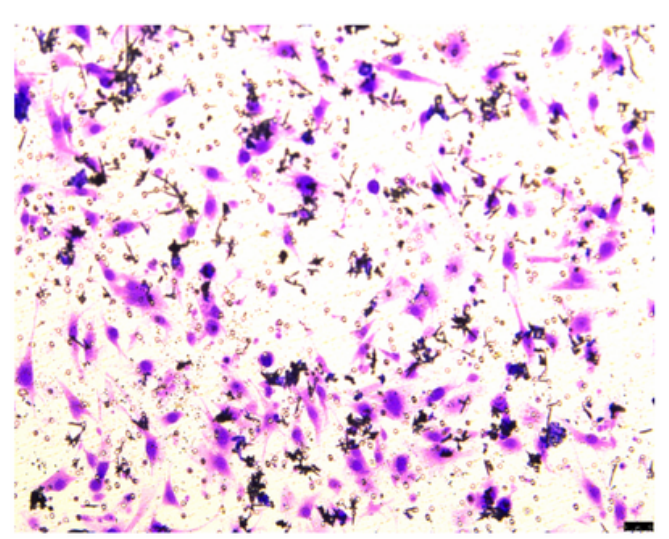

+ MSC cell

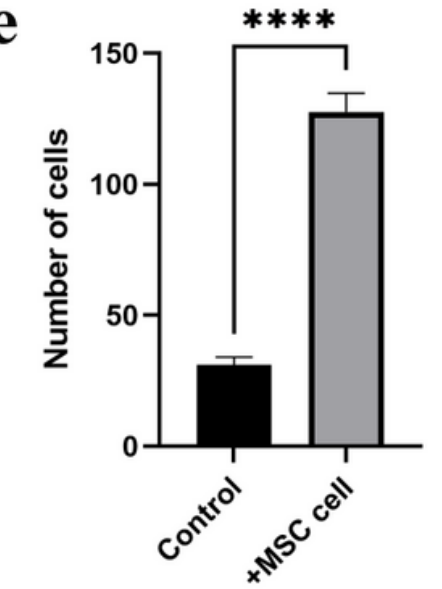

Figure 6 
MSCs promotes the migration and proliferation of lung fibrotic cells in vitro. (a-c) The MSCs was harvested and added to the culture medium of lung fibrosis cells. (a) The two types of cells are mixed and cultured at a ratio of 1:1. (b-c) Wound healing assay. (d-e) Transwell invasion assay. All results are represented as mean \pm SD. $n=5$ per experimental group. ${ }^{*} * \mathrm{P}<0.001, * \star \star \star P<0.0001,1$-way ANOVA followed by Fisher's LSD post hoc analysis.

a

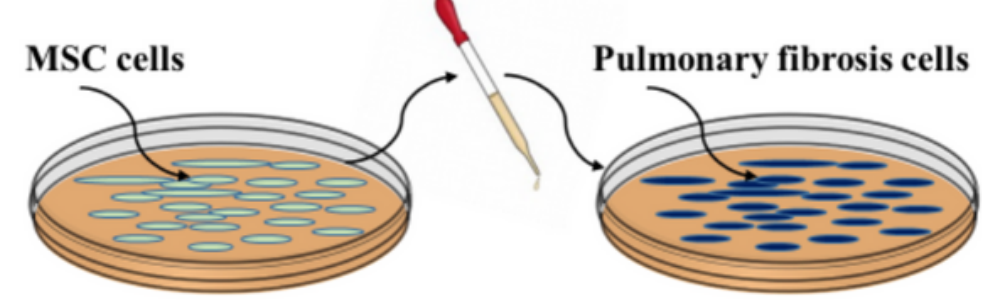

b
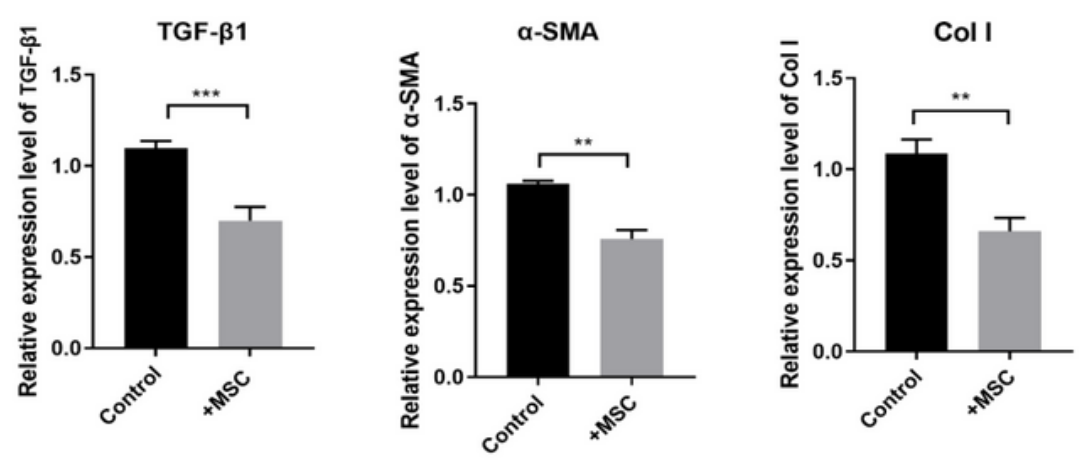

c

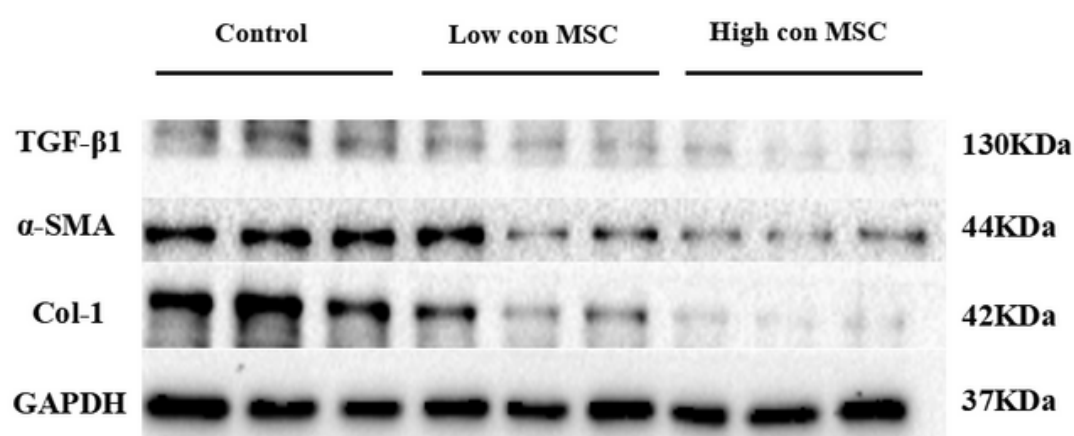

d

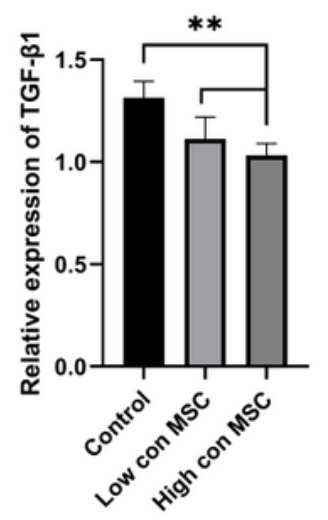

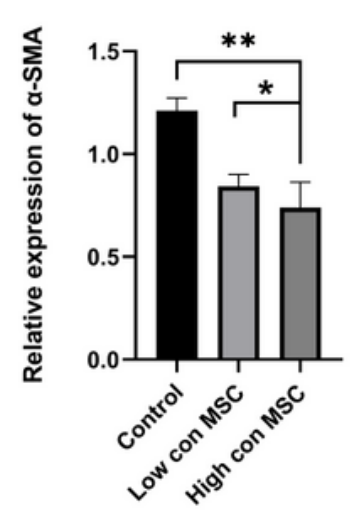

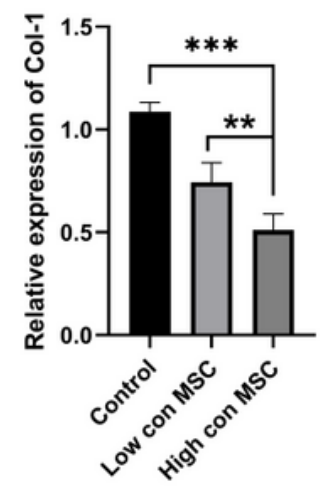

Figure 7 
MSC supernatant reduces the expression of fibrosis-related genes and protein levels of pulmonary fibrosis cells. (a) The MSC supernatant was harvested and added to the culture medium of lung fibrosis cells. (b) qRT-PCR analysis showed that MSC supernatant can reverse the formation of pulmonary fibrotic cells induced by TGF- $\beta 1$. Expression of TGF- $\beta 1 \square a-S M A \square$ and collagen type I levels ( $n=3$ per group). (c-d) The relative protein levels at different doses of MSC supernatant. Expression of TGF- $\beta 1 \square a-S M A \square$ and Col $\mathbb{Z}$ levels ( $n=3$ per group). Data are representative of 5 independent experiments, mean \pm SD. $n=5$ per experimental group. ${ }^{\star} \mathrm{P}<0.05 ;{ }^{\star *} \mathrm{P}<0.01,{ }^{\star \star \star} \mathrm{P}<0.001,1$-way ANOVA followed by Fisher's LSD post hoc analysis. 